\title{
Life events, poverty, and car ownership in the United States: A mobility biography approach
}

\author{
Nicholas J. Klein \\ Cornell University \\ n.klein@cornell.edu
}

\author{
Michael J. Smart \\ Rutgers, the State University of New Jersey \\ mike.smart@rutgers.edu
}

\begin{abstract}
What causes families to buy or give up a car in the U.S.? Following the mobility biography approach, we use a nationally representative panel data set, the Panel Study of Income Dynamics (PSID), to examine the role of life events and changes in the built environment and compare the effect that these events have on changes in car ownership. We find that coupling, graduating from college, and the birth or adoption of a child all are associated with increases in car ownership, while breaking up is associated with decreases in car ownership. Moving to or away from transit-rich, dense, walkable neighborhoods matters but only when one moves to a very different type of neighborhood. We also find that life events have a stronger association with gaining a car for non-poor families than for families in poverty. Life events are windows of opportunity when families reevaluate their travel patterns. Interventions at these critical junctures could be an expedient way to decrease car ownership and its attendant problems, especially when combined with improving alternatives to the automobile.
\end{abstract}

Article history:

Received: November 2, 2018

Received in revised form:

March 6, 2019

Accepted: May 6, 2019

Available online: May 21, 2019

\section{Introduction}

The first author of this manuscript recently purchased a car for the first time. What had changed in his life? He and his family moved from New York City to a small town before he started a new job. Did they buy a car because of the new job, because they moved to a place without a robust transit system, or because of something else? In this paper, we examine how life events-coupling, a new child, breaking up, gaining or losing a job, declining health, and more-are associated with changes in car ownership, and we compare the effect of these life events with changes in the built environment.

Studying individuals over time and examining how life events relate to travel behavior is known as the "mobility biography" or "life course" approach. For many years, sociologists, psychologists, and health researchers have conducted life course research (Elder \& Giele, 2009), but transportation researchers have only recently adopted this approach. Mobility biography research differs from traditional travel behavior research, which often analyzes travel behavior as a function of individual socioeconomic characteristics, the built environments where individuals live, and their attitudes and preferences at a point in time. The mobility biography turns this approach on its head to examine individuals and families over time. This approach builds on the notion that most travel behavior is habitual and, as with most habits, our travel routines are stable until something leads us to pause and reflect on our choices

Copyright 2019 Nicholas J. Klein \& Michael J. Smart

http://dx.doi.org/10.5198/jtlu.2019.1482

ISSN: $1938-7849$ | Licensed under the Creative Commons Attribution - Noncommercial License 4.0

The Journal of Transport and Land Use is the official journal of the World Society for Transport and Land Use (WSTLUR) and is published and sponsored by the University of Minnesota Center for Transportation Studies. 
(Verplanken, Aarts, \& van Knippenberg, 1997). Studying the same people across time foregrounds contextual changes such as moving to a different type of neighborhood, having a child, and the loss of a partner as the kinds of life events that could lead to changes in car ownership, travel behavior, or both.

We use a biennial panel data set from the United States, the Panel Study of Income Dynamics (PSID) (2015), to examine how life events affect car ownership over many years. Our data set is a nationally representative sample of over 9,000 families spanning six biennial waves from 2003 through 2013. (We use the term families rather than households because the PSID follows family members over time.) The data set includes detailed information on automobile ownership, and we make use of the panel nature of the data to identify the life events that may influence decisions about car ownership. We pay particular attention to movers to evaluate the effect of changes in the built environment, since it may play an important role in travel behavior and is the focus of policy (Ewing \& Cervero, 2010), and we compare these effects with other life events. We also make use of the fact that the PSID includes many families in poverty to examine if, and how, life events influence car ownership for families in poverty and those who are better off.

We find that life events can have substantial effects on the likelihood of families gaining or shedding a car and that many of these are larger than the effects of changes in individual aspects of the built environment, though changes in multiple aspects of the built environment can have a substantial impact on car ownership. Among the carless, forming a new couple, graduating from college, and the birth or adoption of a child are the life events that have the biggest effect on obtaining a car. Losing a partner due to a breakup, divorce, or death has the largest effect on decreasing car ownership. For transportation planners, targeted interventions that coincide with life events offer an additional tool in their efforts to decrease car ownership.

When we separately analyzed families in poverty and those who are better off financially, we find that the effect of life events differs. For poor families, life events have a small effect on the likelihood of gaining a car compared with more affluent families. The opposite is not necessarily true for decreasing car ownership. When it comes to giving up cars, some events have a larger effect for affluent families than for those in poverty, while the opposite is true for other events.

In the next section, we describe the mobility biography research on car ownership. We then present our analytical approach and describe the data we use. We then discuss our findings on the relationship between life events and changes in car ownership. We conclude with a discussion of the implications of our findings for public policy.

\section{The mobility biography perspective on car ownership}

The mobility biography approach offers a theoretical framework for examining how a variety of events, both internal and external to the household, change daily travel. Central to this theory is the assumption that much of daily travel is habitual (Gärling \& Axhausen, 2003; Verplanken et al., 1997). People generally use the same modes and routes from day to day, rather than approaching each journey as a utility function to be maximized. Habits rarely change without something disrupting the routine. In the early 2000s, Axhausen (2002), Lanzendorf (2003), and van der Waerden, Timmermans, and Borgers (2003) articulated the theory and conducted early studies using this approach, also known as the "life course" perspective. This body of research, mostly based in Europe, has produced a wealth of evidence supporting this framework (see literature reviews Chatterjee $\&$ Scheiner, 2015; Müggenburg, Busch-Geertsema, \& Lanzendorf, 2015; Rau \& Manton, 2016; Scheiner, 2017, 2018).

For researchers, this approach suggests studying the events in a person's life that lead to changes in habits, rather than studying factors associated with individual journeys. Studying travel behavior as more than just an "in the moment" decision is not new. Scholars have long recognized that higher-level factors, such as one's life cycle, can structure the available options for individuals' daily travel (Cullen, 
1978; Kitamura, 2009; Krizek \& Waddell, 2002; Salomon, 1983; Salomon \& Ben-Akiva, 1983; Waddell, 2000; Walker \& Li, 2007). A host of researchers have examined how specific events alter travel behavior. For example, research on residential relocation (Cao, Mokhtarian, \& Handy, 2007; Handy, Cao, \& Mokhtarian, 2005), changes in the transportation system (Fujii \& Kitamura, 2003), and employers instituting staggered work hours (Giuliano \& Golob, 1990) all focus on the role of events in changes in behavior.

Mobility biography research has consistently found that life events coincide with changes in travel behavior and car ownership. Changes in car ownership rarely happen without a life event (Clark, Chatterjee, \& Melia, 2015). Changes in income, changes in the number of adults of driving age, forming a couple, breaking up, and the birth of a child are all associated with changes in car ownership (Dargay \& Hanly, 2007; Oakil, Manting, \& Nijland, 2018; Prillwitz, Harms, \& Lanzendorf, 2006; Scheiner \& Holz-Rau, 2013a). These processes may not be symmetric; for instance, households increase car ownership as incomes rise to a greater degree than they decrease car ownership when incomes fall (Dargay, 2001; Müggenburg et al., 2015). Changes in car ownership are also strongly linked to changes in employment and relocation, which often coincide (Beige \& Axhausen, 2012; Lanzendorf, 2003; Rau \& Manton, 2016; van der Waerden et al., 2003). Moreover, while a car purchase is frequently associated with childbirth (Prillwitz et al., 2006), it may precede the birth (Oakil, Ettema, Arentze, \& Timmermans, 2014). There is some evidence that declining health due to age is associated with declines in car ownership (Clark, Lyons, \& Chatterjee, 2016) and there is a much larger literature on driving cessation among the elderly (e.g., Edwards, Lunsman, Perkins, Rebok, \& Roth, 2009; Rosenbloom, 2001).

Methodologies that focus on change over time are particularly useful for mobility biography research, including panel, pseudo-panel, and retrospective surveys as well as qualitative interviews. Dargay and Hanly (2007), writing about their research using panel data, draw out the differences between their approach and the more common approach of using more readily available cross-sectional surveys: "we are specifically concerned with changes in the behavior of the individual or household as their socioeconomic and demographic characteristics change rather than differences between individuals with different characteristics" ( $p$ 934). Qualitative research within this framework has uncovered additional moments associated with changes in travel that may not be included in many surveys (examples include Clark et al., 2016; Jones, Chatterjee, \& Gray, 2014; Miles, Moore, \& Muir, 2014; Rau \& Sattlegger, 2017; Sattlegger \& Rau, 2016). Some of these unexpected events include living abroad (Delbosc \& Nakanishi, 2017) and being mugged (Behrens \& Mistro, 2010). Qualitative research also suggests that treating life events as discrete events oversimplifies how travel behavior evolves. For example, the effects of having a child on a family's travel behavior unfold over several years, beginning during pregnancy, and gradually change as the child ages (Lanzendorf, 2010).

Residential relocations and the related changes in the built environment are critical life events in mobility biography studies, though approaches to dealing with the built environment vary. Some studies have measured the effect of moving to a suburb or urban center (Prillwitz et al., 2006), others examine moving to cities with different "mobility cultures" (Klinger \& Lanzendorf, 2016), while still others include detailed measures of accessibility (Busch-Geertsema \& Lanzendorf, 2017; Scheiner \& Holz-Rau, 2013b, 2013a; Zhao \& Zhang, 2018). Few studies have explicitly compared the effects of changes in the built environment to other life events. Clark et al. (2015) are an exception, finding that changes in the built environment are associated with changes in car ownership and that, in general, these effects are smaller than the effects associated with life events. Without controlling for attitudes and preferences for travel and neighborhood, unraveling the link between relocation and changes in travel behavior can be difficult (Cao, Mokhtarian, \& Handy, 2009; Schwanen \& Mokhtarian, 2005). Recent work has begun to integrate attitudes and preferences associated with residential self-selection into the mobility biography framework (e.g., Scheiner, 2014b; Scheiner \& Holz-Rau, 2013b) 
Our approach seeks to include detailed information about the built environment characteristics across panel waves and to examine the effect of built environment changes along with those associated with life events. In addition to our analysis of the full sample of respondents in the PSID, we extend the mobility biography research in new directions by comparing the effects of life events and the role of the built environment by poverty status, a topic which has previously not been examined in mobility biography research. Yet there is a strong reason to believe that the relationship between life events, the built environment, and car ownership may vary considerably by income group. In the U. S., car ownership is strongly tied to income; families living below the poverty line are much less likely to own cars, and more likely to transition into and out of car ownership (Brown, 2017; Klein \& Smart, 2017).

We are also among the first to examine the role of life events in a U.S. context, where the effect of both the built environment and life events may be very different than in the frequently studied European context (see also Janke \& Handy, 2019). Given the lower quality of public transit, fewer parking restrictions, and more limited bicycle and pedestrian networks, the effects of changes in the built environment may be more muted in the U.S. context than in the European context (Buehler, Pucher, Gerike, \& Götschi, 2017), where most of the mobility biography research has been conducted. Finally, our analysis considers how changes in one's health can influence car ownership decisions, an understudied topic in the literature (cf. Clark et al., 2016).

\section{Data}

To analyze the role that life events play in car ownership within families over time, we use six biennial waves, 2003 through 2013, from a confidential version of the Panel Study of Income Dynamics (Panel Study of Income Dynamics, restricted use data, 2015). Since 1968, the PSID has been surveying a representative sample of U.S. families and their offspring, primarily focusing on questions of income and expenditures (McGonagle, Schoeni, Sastry, \& Freedman, 2012). Initially an annual survey, the PSID transitioned to biennial waves after 1997. Through the addition of supplemental samples and natural growth, the survey has grown from 5,000 to over 9,000 families and more than 23,000 people. While the PSID has a very high response rate (the overall response rate is 91 percent and a 94 percent waveto-wave response rate), there has been a cumulative loss of roughly 40 percent (Johnson, McGonagle, Freedman, \& Sastry, 2018). However, when using the survey weights to account for these changes, the PSID remains representative and comparable with other national surveys. Over the past few decades, the PSID has become an important data source for life course research, particularly in health studies (Sastry, Fomby, \& McGonagle, 2018). We limit our study to the waves from 2003 to 2013 because they include consistent questions about car ownership and life events. Because the PSID is a biennial survey, we are not able to identify the exact timing of life events or car ownership, which may muddle the effect we observe, or we may misattribute causation between life events and changes in car ownership that happen to occur within the two-year window.

\section{$4 \quad$ Approach}

We model car ownership growth and decline separately, as others have done (Clark et al., 2015; Oakil et al., 2014). Modeling car acquisition and loss separately allows us to uncover life events that increase the likelihood of gaining and shedding a car, as we find with changes in employment. Other model forms, such as an ordered logistic regression, would not provide this insight. We also use a population-averaged autoregressive logit model to address serial correlation and heteroscedasticity in the panel data.

We focus on changes in family-level rather than individual-level car ownership. In the PSID, families are people living together typically related by blood, marriage, or adoption, excluding roommates (unless they are permanently living with the family). A single person living on their own or a multigen- 
erational family living together could be a family unit. Using the family as the unit of analysis is in line with calls to situate life events within a family or household (Rau \& Sattlegger, 2017). Our outcome variable indicates an increase or decrease in the number of cars in the family.

We also analyzed changes in the ratio of cars to adults rather than the number of cars, and we present these results in the appendix. Using different outcome variables presents trade-offs. A ratio outcome variable may do a better job of capturing how families negotiate decisions about sharing a car, but it makes interpreting the effect of life events that simultaneously change the household structure and car ownership more difficult. For example, when a couple that owns one car breaks up, the level of car ownership increases for the person who keeps the car (from 0.5 to 1 car per adult) despite the number of cars remaining the same.

We based our decision about which life events to include in our model on theory, previous research, and data availability. Some important life events, such as obtaining a driver's license and changing jobs, are not available in the PSID. The following subsections describe the events we include in our models related to changes in the built environment, income and wealth, family composition, family structure, education and employment, and health.

\subsection{Family life events}

We include changes to family composition, education and employment, and health as events in our models. We include changes in relationship status, namely coupling up and de-coupling (due to a breakup, divorce, or death of a partner). We derived these variables from the changes in the survey respondents' couple status from wave to wave. We identified the formation of a couple when the head of the family has a new partner via either marriage or unmarried cohabitation. Conversely, we identify a decoupling when the head is no longer in a couple, through separation, divorce, or the death of a partner. To account for changes in car ownership that may arise from the presence of children, we include life events marking children's entrance and exit from the family. First, we identify the birth or adoption of a child, which we define as families that have no children in one wave and subsequently have one or more children under five in the next wave. Second, we indicate when the head of the household becomes an empty nester. We identify empty nests when children become financially independent from the parents, at which point the PSID starts treating these children as a separate family unit from the parents. Our empty nest variable may be an imperfect match with the more common use of empty nest to indicate the last child leaving home - for instance by going away to college - even if they remain financially tied to their parents.

Employment and education events may also influence car ownership, so we include measures of these. Because our unit of analysis is the family, we identify changes between panel waves when either the head or partner/spouse, if present, graduates from college, gains a job, loses a job, or retires. For these life events, we consider the head and partner/spouse, if present, together, and mark the event as having occurred if it happens to either person. Changes in education are straightforward since the survey asks about respondents' educational attainment in each wave. For the employment changes, we rely on changes in the head's or partner/spouse's employment status. We identify that the head or partner/spouse has gained a job when one or both transitions from not working to being employed in the subsequent panel. Similarly, we indicate that a family member has lost a job when they transition from working to either being "laid off" or "looking for work/unemployed." A family member retires when they transition from working to retirement.

Finally, we include self-assessed measures of the health of the family head and partner/spouse when

present. Here we rely on the PSID's questions about general health and difficulty walking. As we did with the education and employment measures, we consider the head and partner/spouse, if present, 
together. For our measure of self-assessed health, we note when either one's general health transitions from excellent, very good, or good to fair or poor between panel waves. We also identify when the head or partner/spouse's response about having difficulty walking (a yes/no question) changes. Because these health conditions are reversible, we code the variable as zero for no change, one for those who developed health problems, and negative one for those whose health problems have resolved.

Because we expect those without a car to be considerably more likely to acquire one than those who already have at least one car, we interact the family life events with being carless in the previous panel wave in our model of increasing car ownership. We do this because we expect the marginal utility of a family's first car to be, on average, considerably greater than that of subsequent cars, thus implying a positive independent effect of carless status on the acquisition of a car.

We chose not to include age as an independent variable in our models. Here we follow the lead of Scheiner and Holz-Rau (2013a), who argue that age is a proxy for life course events such as child-rearing, employment, and health-related concerns, which we include in our models. We separately tested a model that includes age and discuss the results in the Appendix.

We use a dummy variable to indicate whether the family moved since the previous wave. We include this because we expect that the simple fact of moving - above and beyond the associated changes in the built environment-maybe be a time of reflection when people reconsider long-standing travel patterns and habits, even if the built environment characteristics do not change much. We also include moving as a dummy variable because we cannot capture everything with our data. For example, someone could move to a neighborhood where the transit level of service appears to be the same, but the new home is near a bus stop with direct service to the workplace.

\subsection{Built environment variables}

We measure changes in the built environment with four variables. The confidential version of the PSID allows us to incorporate information about the family's home census tract (spatial enumeration units designed to have 4,000 residents, on average). We include changes in access to jobs via transit, residential population density, a measure of the pedestrian environment, and whether the family moves to or away from New York City (since its residents have uniquely low rates of car ownership for the United States; 55 percent of households are carless compared with 9 percent for the United States). For transit accessibility, we use the number of jobs accessible via public transit and or walking in 30 minutes from the home census tract in 2015. We obtained this from the University of Minnesota Accessibility Observatory (Owen, Levinson, \& Murphy, 2017) and transformed it to a regionally standardized z-score (standard deviations from the core-based statistical area's mean). Population density data come from the 2010 US Decennial Census (U.S. Census Bureau, n.d.). For our measure of the pedestrian environment, we use Walk Score data from 2016, a proprietary measure of walkability based on walking distances to amenities ("Walk Score," 2016), which is highly correlated with non-work pedestrian travel (Manaugh \& El-Geneidy, 2011). We include a dummy variable in our model for a family living in a census tract with a Walk Score greater than 65; we do so based on visual inspection of the data, finding a strongly nonlinear association with car ownership with a cutpoint at roughly a value of 65 , consistent with previous research (Smart, 2018).

Ideally, we would include more details about the built environment, including measures of the family members' work locations. Unfortunately, the PSID does not provide data on workplace location. We also do not have information about parking availability at home or work, nor data on the regional form (sprawling/compact, monocentric/polycentric, and so forth), which we suspect are crucial factors in car ownership decisions. Finally, because our built environment data are time-invariant, we observe changes in the built environment only when families move residences, and thus can comment only on the joint 
occurrence of moving and changes in the built environment, rather than on changes in the built environment in situ, as in the case of expanded transit service to a family's neighborhood. The time-invariant nature of our built environment variables may introduce some noise into our data, though the built environments of most places in the United States likely did not change dramatically over this period (For instance, the mean, median, 25th, and 75th percentile residential density of census tracts in the United States have remained largely unchanged since 1980, as shown in King, Smart, \& Manville, 2019).

\subsection{Other independent variables}

We also include several variables that covary with car ownership. First, we include measures of income and wealth, since they play important roles in car ownership. We include dummy variables indicating the income quintile for the family interacted with the change in income (in thousands) between panel waves. We separately analyze changes in income by quintile, since consumption is nonlinear with respect to income, and lower-income individuals are more apt to respond to additional income (or losses of income) by changing their car ownership levels than are high earners. We also include a logged measure of the family's wealth, i.e., the family's net worth, which includes all the family's assets (minus debts) and may give a better picture of a family's ability to make large purchases, such as a car. We choose a measure of wealth that excludes the value of the family's primary home (though the results do not change measure when we include home value). Second, we include changes in the number of driving-age children (16 to 20 years) and the number of adult family members (grandparents, uncles, aunts, etc., but not including the spouse and adult children). Third, we include measures of car ownership in the previous wave: a dummy variable indicating whether the family had zero cars in the previous wave and a dummy variable indicating that the family had at least one car but had fewer cars than adults. We do so because we expect that the majority of U.S. families that do not have a one-to-one ratio of cars to adults in the family will seek to attain this status (King et al., 2019). Finally, we include year-specific effects in our model to account for temporal influences: for instance, the economic recession beginning in 2008.

\section{$5 \quad$ Results}

Table 1 summarizes the variables used in our models of increasing and decreasing car ownership. The samples we use for these two models are slightly different, as the pools of families that can experience increases and decreases in car ownership are different. The model of decreasing car ownership applies only to families that owned cars in the previous wave, making that sample smaller.

The sample used in the model of car ownership growth (column A), which includes zero-car families, has slightly higher transit access, residential density, and Walk Score and greater likelihood of living in New York City compared to the sample used in the model of decreasing car ownership (column B), which excludes carless families. Income, wealth, and family size also vary between the samples. There are few differences when it comes to life events. The most common life event among the families in our sample is a head or partner/spouse developing poor health (14.6 and 12.9 percent of families, depending on the sample). The next most common life events are changes in employment: becoming employed (11 percent), losing a job (6 percent), and retiring (6 to 7 percent, depending on the sample). 
Table 1. Descriptive statistics for car growth and car decline models, PSID 2003-2013

Increased car ownership

(A)

\begin{tabular}{|c|c|c|}
\hline & & \\
\hline Number of cars & 1.67 & 1.90 \\
\hline Ratio of cars to adults & 0.96 & 1.09 \\
\hline \multicolumn{3}{|l|}{ Changes in car ownership } \\
\hline Increased car ownership & $15.8 \%$ & $15.1 \%$ \\
\hline Decreased car ownership & $19.4 \%$ & $19.7 \%$ \\
\hline Family moved since last wave & $29.6 \%$ & $26.9 \%$ \\
\hline \multicolumn{3}{|l|}{ Built environment } \\
\hline Transit access (regional $z$-score) & -0.04 & -0.10 \\
\hline Residential density (1,000s per sq. mi.), census tract & 4.48 & 3.47 \\
\hline Sharing living where Walk Score $>65$ & $10.9 \%$ & $8.6 \%$ \\
\hline Share living in New York City & $2.0 \%$ & $1.2 \%$ \\
\hline \multicolumn{3}{|l|}{ Family members } \\
\hline Number of adult family (other than head/spouse) & 0.49 & 0.44 \\
\hline Number of driving-age kids (top coded at 3) & 0.17 & 0.18 \\
\hline Income (mean) & 82,133 & 90,072 \\
\hline Income (median) & 57,938 & 66,316 \\
\hline Wealth, excluding home equity (mean) & 280,219 & 304,589 \\
\hline Wealth, excluding home equity (median) & 24,600 & 35,510 \\
\hline \multicolumn{3}{|l|}{ Car ownership last wave } \\
\hline Zero cars & $10.9 \%$ & $0.0 \%$ \\
\hline Sharing cars & $15.8 \%$ & $16.7 \%$ \\
\hline At least one car per adult & $73.3 \%$ & $83.3 \%$ \\
\hline More than one car per adult & $18.6 \%$ & $21.5 \%$ \\
\hline \multicolumn{3}{|l|}{ Life events } \\
\hline Coupling & $2.7 \%$ & $2.4 \%$ \\
\hline De-coupling (breakup / death of partner) & $6.2 \%$ & $6.1 \%$ \\
\hline Empty nest & $4.1 \%$ & $4.0 \%$ \\
\hline New child (birth or adoption) & $2.6 \%$ & $2.6 \%$ \\
\hline Family member graduated from college & $4.0 \%$ & $4.3 \%$ \\
\hline Family member became employed & $10.9 \%$ & $10.7 \%$ \\
\hline Family member lost job & $6.1 \%$ & $5.8 \%$ \\
\hline Family member retired & $6.4 \%$ & $6.6 \%$ \\
\hline Family member developed health issues & $7.0 \%$ & $5.8 \%$ \\
\hline Family member developed difficulty walking & $14.6 \%$ & $12.9 \%$ \\
\hline Observations (persons) & 9,542 & 7,831 \\
\hline Observation (person-years) & 38,277 & 30,879 \\
\hline
\end{tabular}

Note: The sample for Column B is smaller than Column A because we limit models of decreasing car ownership to families that owned at least one car in the previous wave.

Decreased car ownership

(B) 


\subsection{The effects of life events and changes in the built environment on car ownership}

Among carless families, we find that key life events are strongly associated with changes in car ownership. For families that already own cars, most life events have a modest effect on their likelihood of further increasing car ownership, and only a few life events have a large effect on the odds of decreasing car ownership. We find that families obtain or shed cars when they move to a different type of neighborhood. However, this effect is of a large magnitude only when they move to or away from a neighborhood where the built environment has very high levels of transit accessibility, is very dense, and is highly walkable. Smaller changes in these built environment characteristics have little effect when we control for life events.

In this section, we present the results of our analysis in two ways. Table 2 presents the results of the full models, and Figure 1 shows the estimated probabilities of increasing or decreasing car ownership associated with life events. At the top of the chart, we show the baseline effect, the average family's likelihood of increasing or decreasing car ownership between any two panel waves. Notably, these baselines are different for carless and car-owning families. Twenty-seven percent of carless families will increase car ownership between two panel waves; for car-owning families, it is just 15 percent. The baseline likelihood of decreasing the number of cars is 20 percent; this is calculated only for families that own one or more cars.

Table 2. Population-averaged logit models of increasing and decreasing the number of cars, PSID 2003-2013

Increased cars

Family moved since last wave

Change in built environment

Transit access (regional z-score)

Residential density (1,000s per sq. mi.), census tract

Living where Walk Score $>65+(-1,0,+1)$

Living in New York City $(-1,0,+1)$

Change in family members

Number of adult family (other than head/spouse)

Number of driving-age kids (top coded at 3)

Change in income, in thousands, for...

...bottom $20 \%$ of earners
... second $20 \%$ of earners
...third $20 \%$ of earners
...fourth $20 \%$ of earners
...top $20 \%$ of earners

Change in wealth (logged)

Car ownership last wave

Zero cars

Sharing cars

At least one car per adult (ref. category)

\section{Life events}

Coupling

interacted with zero cars last wave

De-coupling (breakup / death of partner)

interacted with zero cars last wave

$1.526^{* * *}$
(A)

Decreased cars

(B)

$-0.126^{* * *} \quad 0.327^{* * *}$

$\begin{array}{ll}-0.081^{* * *} & 0.069^{* * *} \\ -0.002^{* * *} & 0.003^{* * *} \\ 0.077^{* * *} & 0.068^{* * *} \\ -0.450^{* * *} & 0.611^{* * *}\end{array}$

$0.172^{* * *}$

$-0.318^{* * *}$

$0.425^{* * *}$

$-0.567^{* * *}$

$0.004^{* * *}$

$-0.005^{* * *}$

$0.002^{* * *}$

$-0.005^{* * *}$

$0.001^{* * *}$

$-0.002^{* * *}$

$0.0013^{* * *}$

$-0.002^{* * *}$

0.00002

$-0.0001^{* *}$

$0.167^{* * *}$

$-0.144^{* * *}$

$0.636^{* * *}$

$0.962^{* * *}$

$-1.227^{* * *}$

$2.289^{* * *}$

$-0.577^{* * *}$

$-0.785^{* * *}$

$-1.353^{* * *}$

$2.282^{* * *}$ 


\begin{tabular}{|c|c|c|}
\hline Empty nest & $0.483^{* * *}$ & $0.692^{* * *}$ \\
\hline interacted with zero cars last wave & $-0.285^{* * *}$ & \\
\hline New child (birth or adoption) & $0.119^{* * *}$ & $-0.235^{* * *}$ \\
\hline interacted with zero cars last wave & $0.881^{* * *}$ & \\
\hline Family member graduated from college & $0.152^{* * *}$ & $0.338^{* * *}$ \\
\hline interacted with zero cars last wave & $1.260^{* * *}$ & \\
\hline Family member became employed & $0.513^{* * *}$ & $0.301^{* * *}$ \\
\hline interacted with zero cars last wave & $0.318^{* * *}$ & \\
\hline Family member lost job & $0.057^{* * *}$ & $0.467^{* * *}$ \\
\hline interacted with zero cars last wave & $0.487^{* * *}$ & \\
\hline Family member retired & $-0.160^{* * *}$ & $0.175^{* * *}$ \\
\hline interacted with zero cars last wave & $-0.121^{* * *}$ & \\
\hline Family member developed health issues & $-0.080^{* * *}$ & $0.310^{* * *}$ \\
\hline interacted with zero cars last wave & $-0.222^{* * *}$ & \\
\hline Family member developed difficulty walking & $0.081^{* * *}$ & -0.004 \\
\hline interacted with zero cars last wave & $-0.044^{*}$ & \\
\hline \multicolumn{3}{|l|}{ Year } \\
\hline \multicolumn{3}{|l|}{2003 to 2005 (reference year) } \\
\hline 2005 to 2007 & $0.263^{* * *}$ & $-0.191^{* * *}$ \\
\hline 2007 to 2009 & $0.087^{* * *}$ & $-0.174^{* * *}$ \\
\hline 2009 to 2011 & 0.009 & -0.012 \\
\hline 2011 to 2013 & $0.027^{* *}$ & $-0.112^{* * *}$ \\
\hline Constant & $-2.152^{* * *}$ & $-1.658^{* * *}$ \\
\hline Observations (persons) & 9,542 & 7,831 \\
\hline Observation (person-years) & 38,277 & 30,879 \\
\hline Pseudo-R Squared & 0.31 & 0.41 \\
\hline
\end{tabular}

${ }^{*}$ Note: Stars indicate statistical significance: ${ }^{* * *} p<0.01,{ }^{* *} p<0.05,{ }^{*} p<0.1$ 


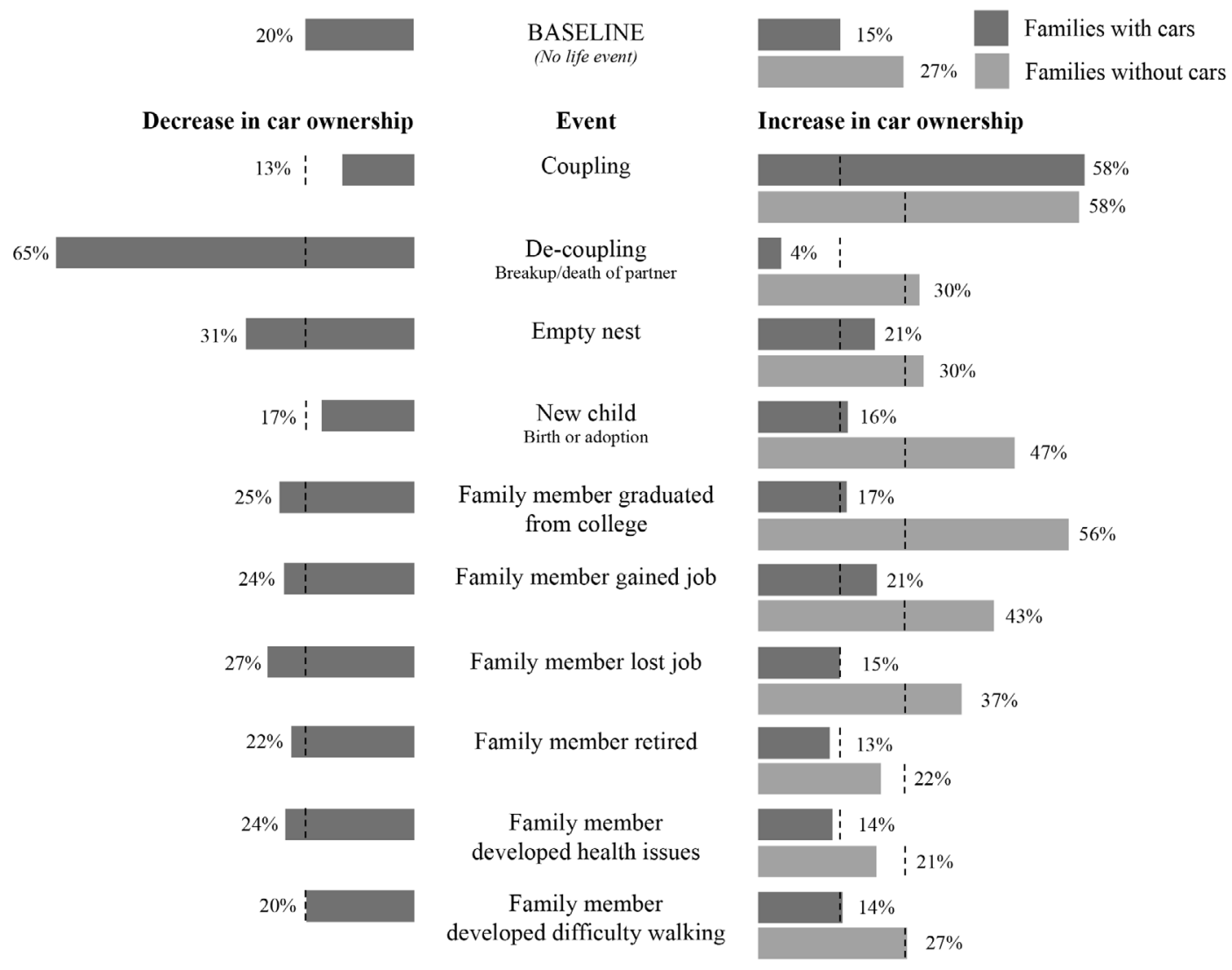

Figure 1. Expected probability of increasing or decreasing car ownership level for life events, PSID 2003-2013

\subsubsection{Changes in family composition}

Gaining or losing a cohabitating partner or spouse has a strong association with increasing and decreasing car ownership, consistent with previous research (e.g., Clark et al., 2015). For families with or without a car, a spouse or partner joining the family is associated with a 58 percent likelihood of the family gaining a car (Figure 1), possibly from the partner/spouse bringing along a car (though we cannot determine this with the data we use). When forming a couple, the likelihood of a family shedding a car is just 13 percent, below the baseline of 20 percent. De-coupling, due to a breakup, divorce, or death of a partner, greatly reduces the likelihood of gaining a car for those who already have one, and slightly elevates it for those who do not. The same event substantially increases the likelihood that a family will see a decline in car ownership, from the baseline of 20 percent to 65 percent.

Having a child is associated with increases in the likelihood of gaining a car and decreases in the likelihood of shedding a car; all else equal, the model predicts that nearly half of carless families will gain a car, compared to 16 percent of car-owning families (only slightly more than the baseline probability of 15 percent, though the coefficient is statistically significant). While the model predicts that 17 percent of new parents will shed a car, this is less than the baseline probability of 20 percent. When children become financially independent from their parents, the odds of gaining and shedding a car increase, though the odds of shedding a car increase more substantially. 


\subsubsection{Employment and education}

When a carless family's head or spouse/partner (if present) graduates from college, the probability of gaining a car more than doubles for carless families. Graduating has a small (but significant) effect on the likelihood of acquiring an additional car for car-owning families and increases the likelihood that families shed cars from 20 to 25 percent.

Changes in employment are also associated with changes in car ownership. When a family member gains a job, the odds of gaining a car increase for all families, though more so for carless families. However, the likelihood that a family will shed a car also increases when a family member becomes employed, though less dramatically. Similarly, losing a job increases the likelihood that a carless family will acquire a car, though it more strongly increases the odds of losing a car. The fact that a job loss leads to a higher likelihood of gaining a car as well as a higher likelihood of shedding a car is surprising, though we note that the inclusion of income as a control variable may help explain this: the result should be interpreted as "the effect of losing a job while income remains the same." Retirement decreases the likelihood of families' acquiring additional cars and slightly increases the likelihood of shedding a car.

\subsubsection{Health}

Our health variables suggest that, when the family's head or spouse/partner develops a general health problem, the family's odds of shedding a car increase, while the odds of acquiring another car (or cars) decrease. When the health problem entails developing difficulties with walking, the effects are very small or not significant.

\subsubsection{Built environment}

Changes in the built environment influence car ownership, but only when a family moves to or away from a neighborhood with excellent access to jobs via transit and with high population density. We suspect that there is a threshold above which these characteristics of the built environment influence car ownership; below the threshold, the effects are minimal. This is further illustrated by the large effects associated with moving to New York City. These moves are associated with much larger odds of giving up one or more cars and with much lower odds of acquiring an additional car. Surprisingly, we find that moving to a neighborhood with a Walk Score over 65 is associated with higher odds of gaining and shedding a car, though the effect is somewhat greater for shedding a car.

While our model results in Table 3 show small though significant effects for our built environment variables, changes in built environment variables do not typically occur in isolation; they change in conjunction with one another (Bento, Cropper, Mobarak, \& Vinha, 2005; Boarnet, 2017; Handy, 2018). We use our model to examine the average effects of several illustrative relocations to demonstrate the combined effect of these variables on car ownership. We model families moving from a census tract with the median transit accessibility to census tracts at the 1st, 5th, 25th, 75th, 95th, and 99th percentile in terms of transit accessibility to jobs. We further adjust both population density and Walk Score for these movers to reflect the average changes associated with moving from the middle transit access tract to tracts in these other percentiles of transit access. We compare these moves to a baseline of a family that moves to a neighborhood with the same transit access, population density, and pedestrian environment.

Figure 2 shows that large changes in car ownership are associated only with relocation from typical neighborhoods to neighborhoods with the highest levels of transit access (from median to the 99th percentile, along with the concomitant increases in population density and Walk Score). When we examine the effect of a move to the 99th percentile of the built environment measures, we find that the likelihood of shedding cars increases from a baseline rate of 20 percent (for families that move but stay in the same 
type of neighborhood) to 32 percent. The same moves have much smaller effects on the likelihood that families increase car ownership, which decreases from 27 percent (the baseline case) to 19 percent for carless families, and from 15 percent to 10 percent for a car-owning family.

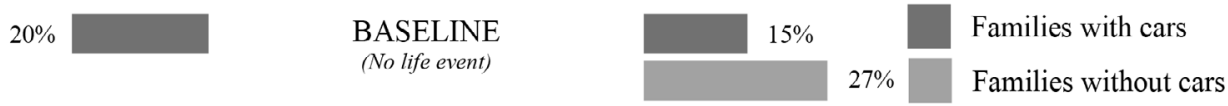

Moved from median tract in terms of transit access to jobs

(with residential density and Walk Score set to average values for median transit access tract)

\section{Decrease in car ownership}

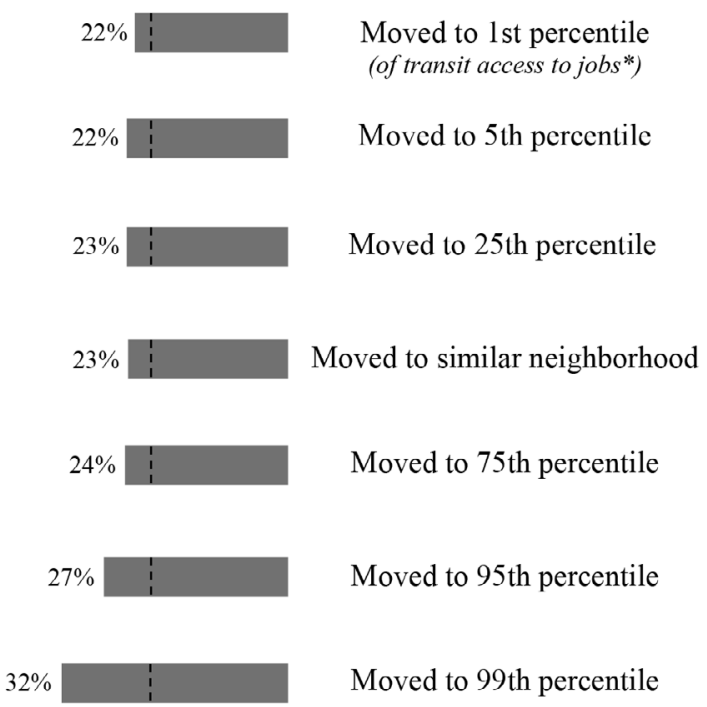

Increase in car ownership
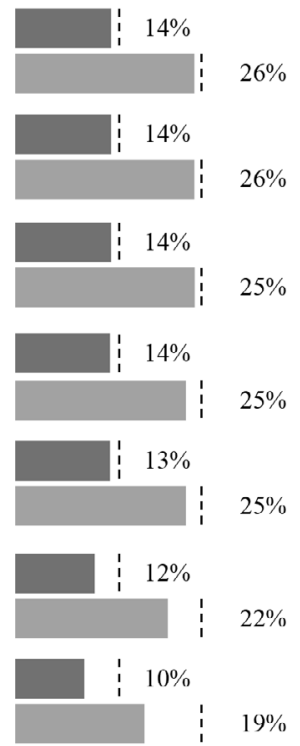

(*residential density and Walk Score set to average values for tracts within that percentile)

Figure 2. Expected probability of increasing or decreasing car ownership for illustrative residential relocations, PSID 20032013

While we observe modest effects for families moving to different types of neighborhoods, this is in part because we include life events in our model, and residential relocation often coincides with life events (53 percent of the time in our sample). When we tested a version of our model without any of our life events, we found that the built environment coefficients are larger in our model of decreasing car ownership. This suggests that research that focuses on residential relocation but not life events may overstate the effect of changes in the built environment.

Other variables included in the model largely conform to expectation, and the model fits the data reasonably well for a difficult-to-predict phenomenon. We estimated a pseudo R-squared by squaring the correlation coefficient of the model's prediction with the observed outcome. The pseudo R-squared values for the models are 0.31 for the model of increasing car ownership and 0.41 for the model of decreasing car ownership. When we compared these with a model that excluded our life events variables, the pseudo R-squared results were lower ( 0.20 and 0.31 respectively). Our family composition and income variables give the expected results. Families adding more children and other adults (aside from the partner/spouse) see higher odds of gaining cars and lower odds of shedding cars. We also find that car ownership in the previous wave has a substantial effect on car ownership in subsequent waves; those with less than one car per adult are more likely to gain one- and less likely to shed one- than are those who already have at least one car per adult. 


\subsection{Life events and poverty status}

In addition to the full sample of families in the PSID, we separately analyze the effects of life events on car ownership transitions by poverty status. We use the US Census poverty definitions, which vary by family size and composition (US Census Bureau, 2018). We classified families as "non-poor" if they are above the poverty threshold in all PSID waves that we analyze and "poor" if they are poor for half or more of the panel waves. Eighteen percent of the full sample are not in either category, meaning they experienced only short bouts of poverty. Table 2 summarizes the car ownership and key events for each subgroup. As expected, families in poverty have lower rates of car ownership and have more frequent changes in car ownership levels (consistent with Klein \& Smart, 2017), lower wealth and income, and more frequent changes in employment status.

Table 3. Descriptive statistics by poverty status, PSID 2003-2013

\begin{tabular}{|c|c|c|c|c|}
\hline & \multicolumn{2}{|c|}{ Not in poverty } & \multicolumn{2}{|c|}{ In poverty } \\
\hline & $\begin{array}{l}\text { Increased car } \\
\text { ownership } \\
\text { (A) }\end{array}$ & $\begin{array}{l}\text { Decreased car } \\
\text { ownership } \\
\text { (B) }\end{array}$ & $\begin{array}{l}\text { Increased car } \\
\text { ownership } \\
\text { (C) }\end{array}$ & $\begin{array}{c}\text { Decreased car } \\
\text { ownership } \\
\text { (D) }\end{array}$ \\
\hline Number of cars & 1.85 & 1.97 & 0.65 & 1.21 \\
\hline Ratio of cars to adults & 1.04 & 1.10 & 0.46 & 0.85 \\
\hline \multicolumn{5}{|l|}{ Changes in car ownership } \\
\hline Increased car ownership & $15.9 \%$ & $15.3 \%$ & $14.1 \%$ & $12.0 \%$ \\
\hline Decreased car ownership & $19.0 \%$ & $19.0 \%$ & $18.9 \%$ & $26.5 \%$ \\
\hline Family moved since last wave & $25.6 \%$ & $24.6 \%$ & $47.4 \%$ & $43.3 \%$ \\
\hline \multicolumn{5}{|l|}{ Built environment } \\
\hline Transit access (regional z-score) & -0.08 & -0.13 & 0.18 & 0.04 \\
\hline Residential density (1,000s per sq. mi.), census tract & 4.37 & 3.50 & 4.88 & 3.40 \\
\hline Sharing living where Walk Score > 65 & $10.1 \%$ & $8.4 \%$ & $14.3 \%$ & $11.0 \%$ \\
\hline Share living in New York City & $2.1 \%$ & $1.3 \%$ & $1.7 \%$ & $0.0 \%$ \\
\hline \multicolumn{5}{|l|}{ Family members } \\
\hline Number of adult family (other than head / spouse) & 0.43 & 0.41 & 0.78 & 0.72 \\
\hline Number of driving-age kids (top coded at 3) & 0.17 & 0.17 & 0.20 & 0.24 \\
\hline Income (mean) & 96,977 & 99,811 & 14,718 & 18,771 \\
\hline Income (median) & 71,196 & 74,514 & 10,677 & 13,539 \\
\hline Wealth, excluding home equity (mean) & 328,675 & 328,877 & 25,293 & 51,518 \\
\hline Wealth, excluding home equity (median) & 328,675 & 47,970 & 62 & 2,120 \\
\hline \multicolumn{5}{|l|}{ Car ownership last wave } \\
\hline Zero cars & $5.6 \%$ & $0.0 \%$ & $46.8 \%$ & $0.0 \%$ \\
\hline Sharing cars & $14.8 \%$ & $15.3 \%$ & $17.5 \%$ & $31.5 \%$ \\
\hline At least one car per adult (ref. category) & $79.6 \%$ & $84.7 \%$ & $35.7 \%$ & $68.5 \%$ \\
\hline More than one car per adult & $20.9 \%$ & $22.4 \%$ & $5.1 \%$ & $10.2 \%$ \\
\hline \multicolumn{5}{|l|}{ Life events } \\
\hline Coupling & $2.4 \%$ & $2.3 \%$ & $2.9 \%$ & $2.5 \%$ \\
\hline De-coupling (breakup / death of partner) & $5.7 \%$ & $5.6 \%$ & $7.7 \%$ & $9.2 \%$ \\
\hline Empty nest & $3.9 \%$ & $3.9 \%$ & $5.3 \%$ & $4.6 \%$ \\
\hline New child (birth or adoption) & $2.6 \%$ & $2.6 \%$ & $2.1 \%$ & $1.7 \%$ \\
\hline Family member graduated from college & $4.3 \%$ & $4.5 \%$ & $1.6 \%$ & $2.4 \%$ \\
\hline
\end{tabular}




\begin{tabular}{lcccc}
\hline Family member became employed & $9.7 \%$ & $9.8 \%$ & $14.8 \%$ & $17.4 \%$ \\
\hline Family member lost job & $5.0 \%$ & $5.0 \%$ & $10.3 \%$ & $11.5 \%$ \\
\hline Family member retired & $6.6 \%$ & $6.7 \%$ & $5.2 \%$ & $5.2 \%$ \\
\hline Family member developed health issues & $5.7 \%$ & $5.2 \%$ & $14.4 \%$ & $12.3 \%$ \\
\hline Family member developed difficulty walking & $12.8 \%$ & $11.9 \%$ & $25.0 \%$ & $21.8 \%$ \\
\hline Observations (persons) & 6,764 & 6,251 & 1,225 & 517 \\
Observation (person-years) & 27,768 & 25,425 & 4,627 & 1,646 \\
\hline
\end{tabular}

Note: The sample for Column B and D are smaller than A and C because we limit the models of decreasing car ownership to families that owned at least one car in the previous wave.

We find that life events are more consequential for families in poverty. We compared the share of changes in car ownership that coincide with a major life event for the full sample as well as for non-poor and poor samples. (Our life events included: moving, changes in couple status, having a new child, becoming an empty nester, changes in employment status, and changes in health.) While 66 percent of the changes in car ownership coincided with a life event in the full sample, slightly fewer, 63 percent, coincided among the non-poor. A much higher share, 81 percent, of car ownership changes coincided with life events among families in the poor sample. This suggests qualifying the finding by Clark et al. (2015) that "the probability of any car ownership level change occurring in the absence of a life event is quite low." Life events are less likely to coincide with changes in car ownership for those with more economic resources.

In our models, we find that more affluent families are much more likely to increase car ownership when they have a life event, except in the case of losing a partner. The models are identical to those presented above, differing only in the sample. We present the probabilities of life events leading to changes in car ownership for both poor and non-poor families in Figure 3. Families that are never in poverty have more resources and can more easily purchase a car when they form a couple, when they have a new child, when someone in the family graduates from college, or even when someone loses a job. The biggest differences are when carless, non-poor individuals form a couple: the likelihood of increasing car ownership nearly triples from a baseline of 31 to 80 percent, while poor individuals' likelihood increases from 21 to 38 percent. In the case of coupling, this may reflect not just additional resources but also economic sorting in coupling, whereby non-poor carless individuals couple with other non-poor people, most of whom have a car.

In the models of shedding cars, we do not observe that life events have consistently different effects for poor and non-poor families. The effects of some events, such as the dissolution of a relationship and a family member graduating from college, have a larger effect for affluent families than for those in poverty. On the other hand, when a family member loses a job or develops a health issue, the effect on the likelihood to decrease car ownership is larger for poor families.

We chose not to present the same hypothetical relocations to different built environment scenarios as we did for the full sample. Very few poor families in our data set move to neighborhoods with the highest percentiles of transit access and other built environment characteristics. 


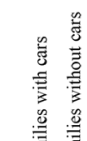

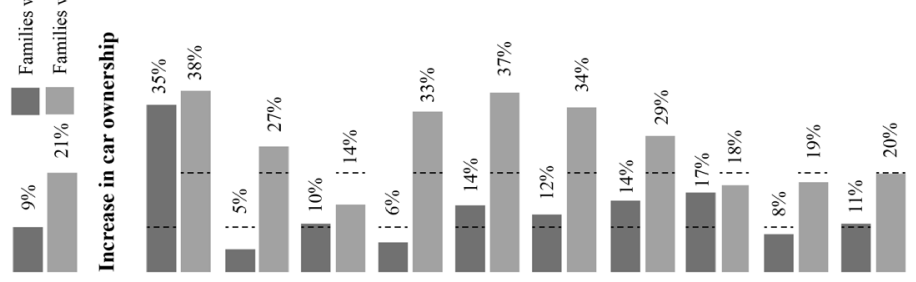
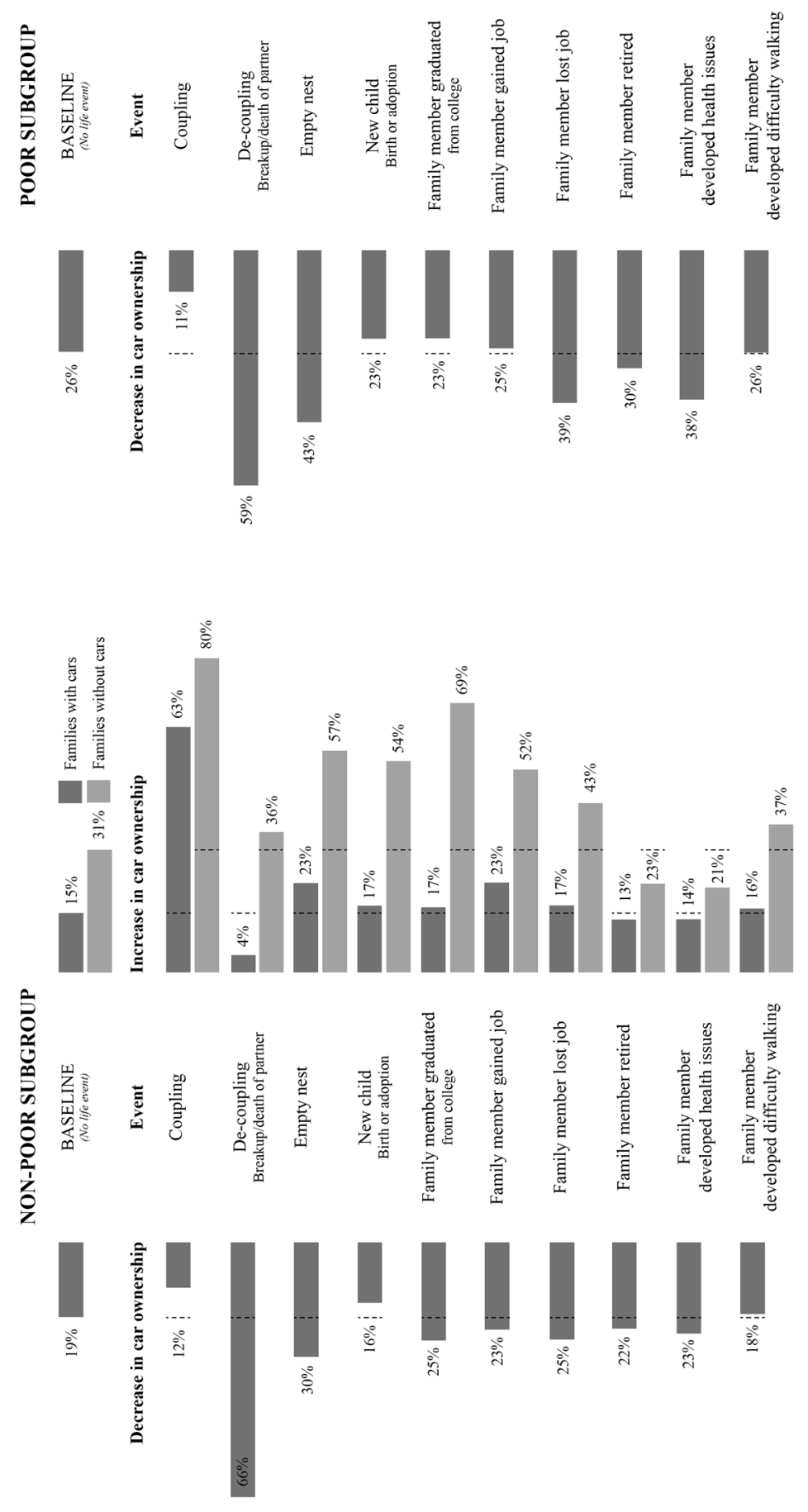

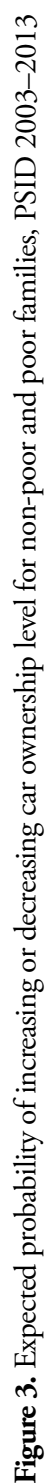




\section{Discussion}

We began this article by asking what led to the first author's buying a car. Two events combined to bring about this change: a new job and a move to a very different built environment. Our research suggests that while both factors can contribute to increasing car ownership, the extreme change in the neighborhood was the primary factor in buying a car. The first author moved from one of the transit-richest and most walkable neighborhoods in the country, with very high residential density, to a neighborhood in a small town with much lower density, limited public transit, and many fewer destinations accessible on foot.

This case is illustrative but also rare. When most families move, they relocate to a similar neighborhood. Radical relocations to or away from transit-rich, dense, and walkable neighborhoods are not nearly as common (the median change in transit access and population density for families that move in our analysis is zero). Moreover, such relocations are less common than life events, which we find frequently coincide with decisions to increase or decrease car ownership. Forming a new couple, graduating from college, and a new child have the largest effect on increasing car ownership among carless families. The dissolution of a relationship or becoming an empty nester is associated with decreasing car ownership. These life events have stronger relationships with car ownership than moving to a census tract with better access to jobs via transit, higher residential density, and a more walkable environment — unless the family relocates and experiences dramatic changes in these built environment factors.

Life events have different effects on poor and affluent families' car ownership. We find that life events have a bigger effect on the likelihood of increasing car ownership among the economically advantaged. This is intuitive. After all, poor families are much less likely to have the capital to buy a car when they couple up, start a new job, or have a baby. At the same time, we find that some life events, like losing a job, are more likely to precipitate shedding cars among disadvantaged families.

We speculate that different sets of events and factors influence poor and affluent families' changes in car ownership and travel behavior more generally. Additional qualitative research could be useful to understand the different reasons why poor families lose cars and how this differs from affluent families. We suspect that that poor families' limited financial resources make them much more susceptible to losing access to a vehicle when their cars require repairs after a crash or regular wear and tear. Poor families are much more likely to purchase used cars that require more maintenance, but they are also less likely to have the resources to make the repairs needed to keep their cars in working order. These types of incidents, along with cars being stolen or repossessed after missing car payments, affect all families, but may be more likely to be the reason that poor families lose access to a car. Interviews, focus groups, and other types of qualitative research would be useful for researchers to understand the dynamics of car ownership among poor families.

Additionally, mobility biography researchers could examine whether life events also have differential effects on changes in travel mode choice, not just car ownership. Previous work has highlighted how life events differently effect men and women's travel modes (Scheiner, 2014a); it stands to reason that there are also differences across the income spectrum.

Our analysis leaves us with many questions about the changes in car ownership when a new couple forms or breaks up. When a new couple forms, we cannot tell whether an increase in car ownership comes from one of the new partners bringing their car with them or from the couple deciding to acquire a car jointly. When a couple dissolves, we cannot tell whether the decrease we observe in car ownership is simply a result of the person who is no longer in the survey taking a car with them. Thus, we may be overestimating the importance of coupling up and breaking up. Untangling the net effect of these life events on car ownership would require survey questions tailored to these instances. 
Given the role of life events, what role can transportation planners play in car ownership? We believe that planners and policy makers should think of life events as "windows of opportunity," when a family is most likely to reevaluate car ownership (Busch-Geertsema \& Lanzendorf, 2017; Thigpen, 2018; Verplanken \& Roy, 2016). Mobility biography research suggests that transitioning to and from college, residential relocations, and the birth or adoption of a child are promising opportunities for transportation planners to foster walking, cycling, and transit habits. An illustrative experiment by Ralph and Brown (2017) shows how informing incoming graduate students about the availability of transit options led to more sustainable travel. Perhaps similar outcomes will be achieved by cities that have begun subsidizing cargo bicycles or e-bikes for new families to encourage avoiding or delaying car purchases associated with a young child (Thomas, 2016).

Other life events, such as the formation or dissolution of a couple, are intensely personal decisions and may not lend themselves to policy interventions. Policies tied to these events are much less clear. It may merely be a matter of doing what transportation planners have been trying to do for ages: make it easier to travel without a car and make driving less attractive. For example, encouraging more familyfriendly housing in transit-rich areas can be viewed through the lens of mobility biography as providing more options for families to avoid buying a car when they have their first child. Other relevant policies are not in the planner's traditional wheelhouse but could also be effective, such as improving schools in our transit-richest neighborhoods, thereby removing a common impetus for new families' flight to the suburbs.

While we find that built environment effects tend to be smaller than those of life events, they remain important. We suggest that researchers interested in the role of the built environment identify threshold effects. We find that changes in the built environment matter only if they are significantly large, but further research can help identify which combinations of built environment characteristics, and at which levels, begin to influence families' choice of car ownership. From a policy perspective, it would be useful to identify tipping points at which accessibility by transit, population density, and other supportive attributes, such as parking constraints, lead to reductions in car ownership. Additionally, the time-invariant nature of our built environment variables may bias our results. Over the study period, not only have some new transit lines opened, but other changes have also occurred: the spatial distribution of jobs, the pedestrian environment, and residential density have likely changed in meaningful ways in a handful of neighborhoods in our dataset, though these changes are absent in our data.

Additionally, we note that the metropolitan-scale built environment likely matters, though we are not able to include this in our models. Previous work on local mobility cultures has shown that both neighborhood-level and metro-level built environments shape travel behavior (Klinger \& Lanzendorf, 2016; Voulgaris, Taylor, Blumenberg, Brown, \& Ralph, 2016). Most American metro areas have pockets of walkable urban areas served by transit, but these are often surrounded by a sea of auto-oriented development, making car ownership quite attractive. Marginal changes to the built environment may thus have only marginal impacts until a sufficient portion of the region is easily accessible without a car. Though our models cannot provide direct evidence of this, we believe that longer-term changes to the built environment can shape the relationship between life events and car ownership by making postcollege life, for instance, as easily accomplished without a car as college life is for many.

We urge researchers to parlay the findings from mobility biography research into experiments. Several researchers have begun to do this with transitions to and from schools, workplaces, and residential relocations, but life events might also represent possibilities for interventions (Ralph \& Brown, 2017; Verplanken \& Roy, 2016). Working with institutional employers, researchers could experiment with mobility programs. Transportation scholars are well positioned to conduct randomized-control studies of a travel demand management program for students and new employees at a university. 
Finally, we suggest that narrative methods offer a rich set of possibilities for future research, as some have begun to do (Jones et al., 2014; Miles et al., 2014; Sattlegger \& Rau, 2016). This approach foregrounds moments of change that are critical to the individual but may not be in included in public data sets.

\section{Acknowledgements}

Thanks to Michael Manville, Kelcie Ralph, Linda Shi, Samantha Matuke, Senna Phillips, and the anonymous reviewers for their helpful comments. The remaining errors are ours.

The National Institutes of Health supported the collection of the PSID data used in this study under grant number R01 HD069609 and National Science Foundation award number 1157698. We also thank the Accessibility Observatory at the University of Minnesota for making data on job accessibility by public transit available.

\section{Data availabilty}

The data used by the researchers is restricted. 


\section{References}

Axhausen, K. W. (2002). A dynamic understanding of travel demand: A sketch. Arbeitsberichte VerkehrsUnd Raumplanung, 119, 1-20. doi.org/10.1108/9781786359520-001

Behrens, R., \& Mistro, R. D. (2010). Shocking habits: Methodological issues in analyzing changing personal travel behavior over time. International Journal of Sustainable Transportation, 4(5), 253-271. doi.org/10.1080/15568310903145170

Beige, S., \& Axhausen, K. W. (2012). Interdependencies between turning points in life and long-term mobility decisions. Transportation, 39(4), 857-872. doi.org/10.1007/s11116-012-9404-y

Bento, A. M., Cropper, M. L., Mobarak, A. M., \& Vinha, K. (2005). The effects of urban spatial structure on travel demand in the United States. The Review of Economics and Statistics, 87(3), 466-478. doi.org/10.1162/0034653054638292

Boarnet, M. G. (2017). Land use, travel behavior, and disaggregate travel data. In G. Giuliano \& S. Hanson (Eds.), The geography of urban transportation (4th edition, pp. 139-163). New York: The Guilford Press.

Brown, A. E. (2017). Car-less or car-free? Socioeconomic and mobility differences among zero-car households. Transport Policy, 60, 152-159. doi.org/10.1016/j.tranpol.2017.09.016

Buehler, R., Pucher, J., Gerike, R., \& Götschi, T. (2017). Reducing car dependence in the heart of Europe: Lessons from Germany, Austria, and Switzerland. Transport Reviews, 37(1), 4-28. doi.org/10. 1080/01441647.2016.1177799

Busch-Geertsema, A., \& Lanzendorf, M. (2017). From university to work life - Jumping behind the wheel? Explaining mode change of students making the transition to professional life. Transportation Research Part A: Policy and Practice, 106(Supplement C), 181-196. doi.org/10.1016/j. tra.2017.09.016

Cao, X., Mokhtarian, P. L., \& Handy, S. L. (2007). Do changes in neighborhood characteristics lead to changes in travel behavior? A structural equations modeling approach. Transportation, 34(5), 535556. doi.org/10.1007/s11116-007-9132-x

Cao, X., Mokhtarian, P. L., \& Handy, S. L. (2009). Examining the impacts of residential self-selection on travel behavior: A focus on empirical findings. Transport Reviews, 29(3), 359-395. doi. org/10.1080/01441640802539195

Chatterjee, K., \& Scheiner, J. (2015, July 19). Understanding changing travel behavior over the life course: Contributions from biographical research. Presented at the 14 th International Conference on Travel Behaviour Research, Windsor, UK. Retrieved from http://www.iatbr2015.org.uk/index. php/iatbr/iatbr2015/paper/view/555

Clark, B., Chatterjee, K., \& Melia, S. (2015). Changes in level of household car ownership: The role of life events and spatial context. Transportation, 43(4), 565-599. doi.org/10.1007/s11116-0159589-y

Clark, B., Lyons, G., \& Chatterjee, K. (2016). Understanding the process that gives rise to household car ownership level changes. Journal of Transport Geography, 55, 110-120. doi.org/10.1016/j.jtrangeo.2016.07.009

Cullen, I. (1978). The treatment of time in the explanation of spatial behavior. In T. Carlstein, D. Parkes, \& N. J. Thrift (Eds.), Human activity and time geography. London: E. Arnold. Retrieved from http://newcatalog.library.cornell.edu/catalog/251697

Dargay, J. M. (2001). The effect of income on car ownership: Evidence of asymmetry. Transportation Research Part A: Policy and Practice, 35(9), 807-821. doi.org/10.1016/S0965-8564(00)00018-5

Dargay, J. M., \& Hanly, M. (2007). Volatility of car ownership, commuting mode and time in the UK. Transportation Research Part A: Policy and Practice, 41(10), 934-948. doi.org/10.1016/j. tra.2007.05.003 
Delbosc, A., \& Nakanishi, H. (2017). A life course perspective on the travel of Australian millennials. Transportation Research Part A: Policy and Practice, 104 (Supplement C), 319-336. doi.org/10.1016/j. tra.2017.03.014

Edwards, J. D., Lunsman, M., Perkins, M., Rebok, G. W., \& Roth, D. L. (2009). Driving cessation and health trajectories in older adults. The Journals of Gerontology: Series A, 64A(12), 1290-1295. doi. org/10.1093/gerona/glp114

Elder, G. H., \& Giele, J. Z. (Eds.). (2009). The craft of life course research. New York: Guilford Press. Retrieved from http://newcatalog.library.cornell.edu/catalog/6715418

Ewing, R., \& Cervero, R. (2010). Travel and the built environment. Journal of the American Planning Association, 76(3), 265-294. doi.org/10.1080/01944361003766766

Fujii, S., \& Kitamura, R. (2003). What does a one-month free bus ticket do to habitual drivers? An experimental analysis of habit and attitude change. Transportation, 30(1), 81-95. doi. org/10.1023/A:1021234607980

Gärling, T., \& Axhausen, K. W. (2003). Introduction: Habitual travel choice. Transportation, 30(1), 1-11. doi.org/10.1023/A:1021230223001

Giuliano, G., \& Golob, T. F. (1990). Using longitudinal methods for analysis of a short-term transportation demonstration project. Transportation, 17(1), 1-28. doi.org/10.1007/BF02125501

Handy, S. (2018). Enough with the "D's" already — Let's get back to "A." Transfers Magazine, (1), 24-26.

Handy, S., Cao, X., \& Mokhtarian, P. (2005). Correlation or causality between the built environment and travel behavior? Evidence from Northern California. Transportation Research Part D: Transport and Environment, 10(6), 427-444. doi.org/10.1016/j.trd.2005.05.002

Janke, J., \& Handy, S. (2019). How life course events trigger changes in bicycling attitudes and behavior: Insights into causality. Travel Behavior and Society, 16, 31-41. doi.org/10.1016/j.tbs.2019.03.004

Johnson, D. S., McGonagle, K. A., Freedman, V. A., \& Sastry, N. (2018). Fifty years of the Panel Study of Income Dynamics: Past, present, and future. The Annal of the American Academy of Political and Social Science, 680(1), 9-28. doi.org/10.1177/0002716218809363

Jones, H., Chatterjee, K., \& Gray, S. (2014). A biographical approach to studying individual change and continuity in walking and cycling over the life course. Journal of Transport \& Health, 1(3), 182-189. doi.org/10.1016/j.jth.2014.07.004

King, D. A., Smart, M. J., \& Manville, M. (2019). The poverty of the carless: Toward universal auto access. Journal of Planning Education and Research, 0739456X18823252. doi. org/10.1177/0739456X18823252

Kitamura, R. (2009). Life-style and travel demand. Transportation, 36(6), 679-710. doi.org/10.1007/ s11116-009-9244-6

Klein, N. J., \& Smart, M. J. (2017). Car today, gone tomorrow: The ephemeral car in low-income, immigrant and minority families. Transportation, 44(3), 495-510. doi.org/10.1007/s11116-0159664-4

Klinger, T., \& Lanzendorf, M. (2016). Moving between mobility cultures: What affects the travel behavior of new residents? Transportation, 43(2), 243-271. doi.org/10.1007/s11116-014-9574-x

Krizek, K., \& Waddell, P. (2002). Analysis of lifestyle choices: Neighborhood type, travel patterns, and activity participation. Transportation Research Record: Journal of the Transportation Research Board, 1807, 119-128.

Lanzendorf, M. (2003). Mobility biographies. A new perspective for understanding travel behavior. Paper presented at the 10th International Conference on Travel Behavior Research (IATBR), Lucerne, Switzerland, August, 2003. 
Lanzendorf, M. (2010). Key events and their effect on mobility biographies: The case of childbirth. International Journal of Sustainable Transportation, 4(5), 272-292. doi.org/10.1080/15568310903145188

Manaugh, K., \& El-Geneidy, A. (2011). Validating walkability indices: How do different households respond to the walkability of their neighborhood? Transportation Research Part D: Transport and Environment, 16(4), 309-315. doi.org/10.1016/j.trd.2011.01.009

McGonagle, K. A., Schoeni, R. F., Sastry, N., \& Freedman, V. A. (2012). The Panel Study of Income Dynamics: Overview, recent innovations, and potential for life course research. Longit Life Course Study, 3(2), 268-284.

Miles, A., Moore, N., \& Muir, S. (2014). Mobility biographies: Studying transport and travel behavior through life histories. In F. Hülsmann, K. Roller, \& R. Gerike (Eds.), Strategies for sustainable mobilities: Opportunities and challenges (pp. 173-188). Farnham, UK: Ashgate Publishing, Ltd.

Müggenburg, H., Busch-Geertsema, A., \& Lanzendorf, M. (2015). Mobility biographies: A review of achievements and challenges of the mobility biographies approach and a framework for further research. Journal of Transport Geography, 46, 151-163. doi.org/10.1016/j.jtrangeo.2015.06.004

Oakil, A. T., Ettema, D., Arentze, T., \& Timmermans, H. (2014). Changing household car ownership level and life cycle events: An action in anticipation or an action on occurrence. Transportation, 41(4), 889-904. doi.org/10.1007/s11116-013-9507-0

Oakil, A. T., Manting, D., \& Nijland, H. (2018). The role of individual characteristics in car ownership shortly after relationship dissolution. Transportation, 1-12. doi.org/10.1007/s11116-018-9857-8

Owen, A., Levinson, D. M., \& Murphy, B. (2017). Access across America: Transit 2015 data [data set]. Retrieved from http://conservancy.umn.edu/handle/11299/183801

Panel Study of Income Dynamics, restricted use data. (2015). Produced and distributed by the Survey Research Center, Institute for Social Research, University of Michigan. Ann Arbor, MI: University of Michigan, Institute for Social Research.

Prillwitz, J., Harms, S., \& Lanzendorf, M. (2006). Impact of life-course events on car ownership. Transportation Research Record: Journal of the Transportation Research Board, 1985, 71-77.

Ralph, K. M., \& Brown, A. E. (2017). The role of habit and residential location in travel behavior change programs, a field experiment. Transportation. doi.org/10.1007/s11116-017-9842-7

Rau, H., \& Manton, R. (2016). Life events and mobility milestones: Advances in mobility biography theory and research. Journal of Transport Geography, 52(Supplement C), 51-60. doi.org/10.1016/j. jtrangeo.2016.02.010

Rau, H., \& Sattlegger, L. (2017). Shared journeys, linked lives: A relational-biographical approach to mobility practices. Mobilities. doi.org/10.1080/17450101.2017.1300453

Rosenbloom, S. (2001). Driving cessation among older people: When does it happen and what impact does it have? Transportation Research Record, 1779(1), 93-99. doi.org/10.3141/1779-13

Salomon, I. (1983). Life-style -A broader perspective on travel behavior. In S. Carpenter \& P. Jones (Eds.), Recent advances in travel demand analysis (pp. 290-310). Aldershot, Hants, England: Gower.

Salomon, I., \& Ben-Akiva, M. (1983). The use of the life-style concept in travel demand models. Environment and Planning A, 15(5), 623-638. doi.org/10.1068/a150623

Sastry, N., Fomby, P., \& McGonagle, K. (2018). Using the Panel Study of Income Dynamics (PSID) to conduct life course health development analysis. In N. Halfon, C. B. Forrest, R. M. Lerner, \& E. M. Faustman (Eds.), Handbook of life course health development (pp. 579-599). doi.org/10.1007/9783-319-47143-3_24

Sattlegger, L., \& Rau, H. (2016). Carlessness in a car-centric world: A reconstructive approach to qualitative mobility biographies research. Journal of Transport Geography, 53(Supplement C), 22-31. doi. org/10.1016/j.jtrangeo.2016.04.003 
Scheiner, J. (2014a). Gendered key events in the life course: Effects on changes in travel mode choice over time. Journal of Transport Geography, 37(Supplement C), 47-60. doi.org/10.1016/j.jtrangeo.2014.04.007

Scheiner, J. (2014b). Residential self-selection in travel behavior: Towards an integration into mobility biographies. Journal of Transport and Land Use, 7(3), 15-28. doi.org/10.5198/jtlu.v7i3.439

Scheiner, J. (2017). Mobility biographies and mobility socialization-New approaches to an old research field. In J. Zhang (Ed.), Life-oriented behavioral research for urban policy (pp. 385-401). Berlin: Springer. doi.org/10.1007/978-4-431-56472-0_13

Scheiner, J. (2018). Why is there change in travel behavior? In search of a theoretical framework for mobility biographies. Erdkunde, 72(1), 41-62. doi.org/10.3112/erdkunde.2018.01.03

Scheiner, J., \& Holz-Rau, C. (2013a). A comprehensive study of life course, cohort, and period effects on changes in travel mode use. Transportation Research Part A: Policy and Practice, 47, 167-181. doi. org/10.1016/j.tra.2012.10.019

Scheiner, J., \& Holz-Rau, C. (2013b). Changes in travel mode use after residential relocation: A contribution to mobility biographies. Transportation, 40(2), 431-458. doi.org/10.1007/s11116-0129417-6

Schwanen, T., \& Mokhtarian, P. L. (2005). What affects commute mode choice: Neighborhood physical structure or preferences toward neighborhoods? Journal of Transport Geography, 13(1), 83-99. doi.org/10.1016/j.jtrangeo.2004.11.001

Smart, M. J. (2018). Walkability, transit, and body mass index: A panel approach. Journal of Transport \& Health, 8, 193-201. doi.org/10.1016/j.jth.2017.12.012

Thigpen, C. (2018). Do bicycling experiences and exposure influence bicycling skills and Attitudes? Evidence from a bicycle-friendly university. Transportation Research Part A: Policy and Practice. doi. org/10.1016/j.tra.2018.05.017

Thomas, A. (2016). A more sustainable minivan? An exploratory study of electric bicycle use by San Francisco Bay Area families. Presented at the Transportation Research Board 95th Annual Meeting Transportation Research Board, Washington DC. Retrieved from https://rid.trb.org/view/1392478

US Census Bureau. (2018, August 16). How the Census Bureau measures poverty. Retrieved from https:// www.census.gov/topics/income-poverty/poverty/guidance/poverty-measures.html

U.S. Census Bureau. (n.d.). US 2010 decennial census, tables "SE:T1. Total population" and "SE:T2. Population density (per sq. mile). "Retrieved from https://www.socialexplorer.com/tables/ACS2013_5yr/ R10983893

van der Waerden, P., Timmermans, H., \& Borgers, A. (2003). The influence of key events and critical incidents on transport mode choice switching behavior: A descriptive analysis. Proceedings of 10th International Conference on Travel Behavior Research, 2003. Retrieved from http://ci.nii.ac.jp/naid/10024449703/

Verplanken, B., Aarts, H., \& van Knippenberg, A. (1997). Habit, information acquisition, and the process of making travel mode choices. European Journal of Social Psychology, 27(5), 539-560.

Verplanken, B., \& Roy, D. (2016). Empowering interventions to promote sustainable lifestyles: Testing the habit discontinuity hypothesis in a field experiment. Journal of Environmental Psychology, 45(Supplement C), 127-134. doi.org/10.1016/j.jenvp.2015.11.008

Voulgaris, C. T., Taylor, B. D., Blumenberg, E., Brown, A., \& Ralph, K. (2016). Synergistic neighborhood relationships with travel behavior: An analysis of travel in 30,000 US neighborhoods. Journal of Transport and Land Use, 10(1) 437-461. doi.org/10.5198/jtlu.2016.840

Waddell, P. (2000). Towards a behavioral integration of land use and transportation modelling. Paper presented at the 9th International Association for Travel Behavior Research Conference, Gold Coast, Queensland, Australia. Retrieved from https://trid.trb.org/view.aspx?id=788682 
Walk Score. (2016). Walk Score website. Retrieved from https://www.walkscore.com/

Walker, J. L., \& Li, J. (2007). Latent lifestyle preferences and household location decisions. Journal of Geographical Systems, 9(1), 77-101. doi.org/10.1007/s10109-006-0030-0

Zhao, P., \& Zhang, Y. (2018). Travel behavior and life course: Examining changes in car use after residential relocation in Beijing. Journal of Transport Geography, 73, 41-53. doi.org/10.1016/j.jtrangeo.2018.10.003

\section{Appendix}

Appendix available as a supplemental file at www.jtlu.org/index.php/jtlu/rt/suppFiles/1482/0 